\title{
Visceral fat and metabolic inflammation: the portal theory revisited
}

\author{
Item, F ; Konrad, D
}

\begin{abstract}
Abdominal (central) obesity strongly correlates with (hepatic) insulin resistance and type 2 diabetes. Among several hypotheses that have been formulated, the 'portal theory' proposes that the liver is directly exposed to increasing amounts of free fatty acids and pro-inflammatory factors released from visceral fat into the portal vein of obese patients, promoting the development of hepatic insulin resistance and liver steatosis. Thus, visceral obesity may be particularly hazardous in the pathogenesis of insulin resistance and type 2 diabetes. Herein, we will critically review existing evidence for a potential contribution of portally drained free fatty acids and/or cytokines to the development of hepatic insulin resistance.
\end{abstract}

DOI: https://doi.org/10.1111/j.1467-789X.2012.01035.x

Posted at the Zurich Open Repository and Archive, University of Zurich

ZORA URL: https://doi.org/10.5167/uzh-66137

Journal Article

Accepted Version

Originally published at:

Item, F; Konrad, D (2012). Visceral fat and metabolic inflammation: the portal theory revisited. Obesity Reviews, 13(2 Suppl):30-39.

DOI: https://doi.org/10.1111/j.1467-789X.2012.01035.x 


\title{
Visceral fat and metabolic inflammation: The portal theory revisited
}

Flurin Item $^{1,2}$ and Daniel Konrad ${ }^{1,2,3}$

${ }^{1}$ Division of Pediatric Endocrinology and Diabetology and ${ }^{2}$ Children Research's Centre, University Children's Hospital, Zurich, Switzerland

${ }^{3}$ Zurich Center for Integrative Human Physiology, University of Zurich, Zurich, Switzerland

Keywords: Obesity, hepatic insulin resistance, lipid metabolism, free fatty acid

\author{
All correspondence and requests for reprint to: \\ Daniel Konrad, M.D. Ph.D. \\ University Children's Hospital \\ Department of Endocrinology and Diabetology \\ Steinwiesstrasse 75 \\ CH-8032 Zurich \\ Tel: ++41-44-266 7966; Fax: ++41-44-266 7983 \\ Email: daniel.konrad@kispi.uzh.ch
}

The authors state no conflict of interest 
Abbreviations

FFA free fatty acid

RBP4 retinol-binding protein 4

IL-1 $\quad$ interleukin $1 \beta$

IL-6 interleukin-6

IL-8 interleukin-8 (mouse homologue KC)

TNF- $\alpha \quad$ tumor necrosis factor- $\alpha$

MCP-1 monocyte chemoattractant protein 1

UCP1 uncoupling protein 1

SOCS3 suppressor of cytokine signaling 3 


\begin{abstract}
Abdominal (central) obesity strongly correlates with (hepatic) insulin resistance and type 2 diabetes. Among several hypotheses that have been formulated the 'portal theory' proposes that the liver is directly exposed to increasing amounts of free fatty acids and pro-inflammatory factors released from visceral fat into the portal vein of obese patients, promoting the development of hepatic insulin resistance and liver steatosis. Thus, visceral obesity may be particularly hazardous in the pathogenesis of insulin resistance and type 2 diabetes. Herein, we will critically review existing evidence for a potential contribution of portally-drained free fatty acids and/or cytokines in the development of hepatic insulin resistance.
\end{abstract}




\section{Introduction}

Obesity results from a longstanding dys-balance of caloric intake exceeding energy expenditure, and is associated with an increased number and size of white adipocytes storing the excessive energy in the form of triglycerides. In recent years it has become evident that adipose tissue has, in addition to its major metabolic tasks, endocrine functions mediated by secretion of different adipokines, cytokines and fat-derived metabolites such as free fatty acids (FFAs). These in turn may act locally, i.e. in an autocrine/paracrine manner, or affect the central nervous system, skeletal muscle, the liver and pancreatic $\beta$-cells to regulate food intake, energy expenditure, and glucose homeostasis $(1,2)$. This endocrine function of adipose tissue contributes to the pathogenesis of detrimental consequences of obesity, such as insulin resistance and type 2 diabetes $(2,3)$. However, not all obese individuals are insulin resistant and diabetic (4), and conversely, conditions with pathologically diminished fat mass (lipodystrophies) are also associated with insulin resistance (5).

Jean Vague was the first to notice that the distribution of fat may influence the predisposition to metabolic diseases (6). Individuals with central obesity (also known as android type or "apple-shaped" obesity) accumulate fat mainly in intra-abdominal and upper thoracic deposits. Numerous epidemiological studies have reported a close association between central obesity, insulin resistance and a cluster of different metabolic diseases (7-13). In contrast, individuals with peripheral obesity (also known as gynoid type or "pear-shaped" obesity) have a predominantly subcutaneous accumulation of adipose tissue in the femoral-gluteal region. Individuals with such type of fat distribution seem to be less susceptible for metabolic complications (14-16) or they may be even protected from insulin resistance and dyslipidaemia (17-19). On the other hand, individuals with a decreased energy storage capacity in peripheral subcutaneous adipose tissue deposit increasing amounts of fat in liver, skeletal muscle and heart and, thus, may be prone to develop insulin resistance and type 2 diabetes as suggested by the "ectopic fat hypothesis" (20). 
All these observations may suggest that it is not merely the increase in adipose tissue mass per se that alters the function of target organs in obesity. Rather, accompanying alterations in the endocrine and metabolic functions as well as the location of adipose tissue may contribute to insulin resistance and diabetes. However, due to inaccuracy in body fat depot measurements and biological variation in fat depot characteristics, the causal relationship of central obesity and (hepatic) insulin resistance is only poorly understood and the impact of different fat depots on the development of metabolic complications is still open to controversy $(21,22)$. In particular, it is unclear whether the different biological nature of visceral fat is driving the apparent stronger association between visceral fat and morbidity or whether it is the mere drainage to the liver as suggested by the 'portal theory'. The present review will discuss current evidence in support of the 'portal theory'.

\section{Functional differences between different fat depots}

Functional analyses have identified differences between various fat depots (23). For example, basal lipolysis rates are higher in adipocytes isolated from omental and mesenteric adipose tissue compared to adipocytes isolated from subcutaneous fat in humans (24-26). Furthermore, the stimulatory effect of catecholamines on lipolysis is stronger while the suppressive effect of insulin is weaker in omental compared to subcutaneous adipose tissue (26,

27). Mechanistically, such observation may be partly explained by the preponderance of stimulatory $\beta$-adrenoceptors over antilipolytic $\alpha$-adrenoceptors and the lower insulin receptor affinity (i.e. its ability to bind insulin) of mesenteric/omental adipocytes $(25,27)$. Consequently, circulating FFA concentration may be higher in the portal circulation as compared to systemic circulation as was shown in lean mice (28). In addition, evidence exists that not only lipolysis, but also lipogenesis varies between fat depots, indicating that varying rates of lipid synthesis contributes to the diverse nature of the different fat depots (29-31). 
There is evidence that adipocytokines may be differently expressed in and secreted from different adipose depots. For example, gene expression and secretion rate of leptin, which regulates food intake and energy expenditure, are two to three times higher in subcutaneous compared to omental adipose tissue, indicating that subcutaneous adipose tissue is the more important source of adipose-derived leptin $(32,33)$. In contrast, secretion of adiponectin, which was found to have insulin-sensitizing and anti-inflammatory properties (34-36), is higher from isolated omental compared to isolated subcutaneous adipocytes (37) albeit the overall contribution from the latter is still higher given its mass. Moreover, its plasma levels decrease in parallel with the progression of obesity and type 2 diabetes (38). Interestingly, adiponectin secretion from omental adipocytes was reduced to a greater degree in more obese individuals, which may explain the decline in plasma adiponectin levels observed in obesity (37). Retinolbinding protein (RBP) 4 and resistin are both associated with insulin resistance and type 2 diabetes $(39,40)$. Importantly administration of recombinant resistin rapidly induced severe hepatic but not peripheral insulin resistance in rats (41). Whereas mRNA expression of resistin appears to be similar from omental and abdominal subcutaneous fat (42), a higher expression rate has been reported for RBP4 in omental compared to subcutaneous fat in human subjects (43). In addition, several pro-inflammatory factors such as interleukin $1 \beta$ (IL-1 $\beta$ ), interleukin-6 (IL-6), interleukin-8 (IL-8; mouse homologue KC), tumor necrosis factor- $\alpha$ (TNF- $\alpha$ ) and monocyte chemoattractant protein 1 (MCP-1) are secreted from adipocytes (as well as non-adipocyte cells such as macrophages), thus contributing to the chronic low-grade inflammatory state often observed in obesity (44). The impact of these cytokines on insulin resistance as well as their depot-specific differences in expression and secretion will be discussed below. Collectively, expression and secretion pattern of various adipocytokines differs between fat depots and hence, given their proposed role in the development of insulin resistance, may partly explain the different impact of central versus peripheral obesity on insulin sensitivity and glucose metabolism. 
Compatible with these functional differences, a multitude of developmental and adipogenic genes are differentially expressed in visceral and subcutaneous adipose tissue both in humans and rodents (45-48). Of note, isolated and cultured preadipocytes maintained their unique gene expression pattern indicating its cell specificity and its independency of tissue environment (49).

Recently, it was proposed that two different types of adipocytes may exist within white adipose tissue: the "genuine" white adipocytes and the brown-in-white "brite" adipocytes. The latter express uncoupling protein 1 (UCP1), a classical marker for brown adipocytes, but otherwise do not possess the full molecular characteristics of brown adipocytes (50). Interestingly, distribution of such "brite" adipocytes differs considerably between different white adipose depots in mice: it is higher in inguinal fat depots and low in perigonadal and mesenteric fat tissue (51). It is plausible that the distinct "brite" adipocyte content of different depots will impact on their function, e.g. their low content may contribute to the increased lipid release of mesenteric adipose tissue. Presently, it is not clear whether 'brite' adipocytes do exist in human white adipose depots and whether these cells could be functionally recruited to prevent or treat obesity (52).

\section{Intra-abdominal adipose tissue comprises different fat depots}

Intra-abdominal fat constitutes only about $10 \%$ of total body fat (53) and includes omental, mesenteric, perirenal and perigonadal fat depots (the latter is only found in rodents, though). Visceral adipose tissue refers to the fat depots surrounding the internal organs (viscera) and is often used synonymously for intra-abdominal fat. However, such generalization may be misleading since not all fat depots located intra-abdominally surround visceral organs. For example, the unique perigonadal fat depot, which has no human correspondent (22), is attached to the testis/epididymis (therefore also known as epididymidal fat tissue) in males and to the fallopian tube in females, which are not considered to be part of the visceral organs. Thus, perigonadal adipose tissue does not comprise visceral adipose tissue in its proper sense even 
though it is often categorized as such (54-57). In agreement with such notion, mRNA expression pattern differ between perigonadal and mesenteric adipocytes (51). Additionally, functional disparities appear to occur as we recently reported differences in lipolysis between perigonadal and mesenteric adipocytes (28).

Moreover, venous drainage differs between intra-abdominal fat depots: Omental (which is insignificant in rodents) and mesenteric fat depots are drained by the portal vein whereas other depots such as the perirenal, the retroperitoneal and the afore-mentioned perigonadal adipose tissue are drained systemically, i.e. by the inferior and superior caval veins (Fig. 1). Thus, the liver is directly exposed to cytokines and FFAs released by portally-drained adipose depots, whereas these factors and metabolites circumvent the liver when released systemically and, thus, reach the liver only after being diluted in the systemic circulation. It was therefore hypothesized in what is known as the 'portal theory' that the exaggerated release of FFAs and proinflammatory cytokines from visceral fat are directly delivered to the liver via portal vein, promoting the development of hepatic insulin resistance and hepatic steatosis in obese individuals $(25,58,59)$.

Thus, there are different intra-abdominal fat depots that have distinguished functional and anatomic properties. Such notion should be kept in mind when analyzing function and metabolism of different intra-abdominal depots in rodents and humans.

\section{Adipose tissue inflammation as a hallmark of obesity}

In obesity, adipose tissue expansion is associated with local infiltration of different types of inflammatory cells (60-63). As in other non-infectious (sterile) inflammatory processes (64), "chronic" inflammatory infiltration of adipose tissue by mainly mononuclear cells seems to be preceded by a transient infiltration with circulating neutrophils, which can be found as early as three days after the initiation of high fat-feeding in mice (65). Subsequently, macrophages gradually become the quantitatively predominant inflammatory cell type infiltrating adipose 
tissue (although other immune cells like $\mathrm{T}$ and $\mathrm{B}$ lymphocytes and mast cells have been reported as well $(44,62,63,66-68))$. These cells secrete different cytokines such as IL-1 $\beta$, IL-6, IL-8, TNF- $\alpha$ and MCP-1, which in turn alter the expression and secretion pattern of adipokines and cytokines in adipose tissue. As a consequence, insulin sensitivity is impaired locally and systemically $(44,69,70)$. Accordingly, it was recently demonstrated that insulin-resistant morbidly obese individuals have a significantly higher number of macrophage infiltration in their omental adipose tissue compared to insulin-sensitive individuals (4). In this scenario, adipose tissue inflammation is suggested to play a role in the induction of adipose tissue dysfunction. Yet, an alternative scenario puts adipose tissue alterations upstream of the recruitment of inflammatory cells into fat tissue and the development of adipose tissue inflammation. A primary event in the latter proposition is increased triglyceride storage (and subsequential fat cell hypertrophy and cell death) and/or increased basal (non-stimulated) lipolysis leading to the recruitment of inflammatory cells, to changes in adipokine production, and to increased cytokine secretion from hypertrophied adipocytes. In this regard, toll-like receptors might play a pivotal role, being activated in macrophages by elevated levels of saturated FFAs (71-73). Alternatively, the latter may activate JNK via induction c-Src clustering within membrane subdomains (74) and/or via activation of double-stranded RNA-dependent protein kinase (PKR) (75). Thus, altered adipokine/cytokine secretion by adipose tissue could constitute both a cause and a consequence of adipose tissue inflammation. Taken together, adipose tissue infiltration with inflammatory cells and the resulting crosstalk with local cells such as adipocytes appear to have a major contribution to the development of obesity-induced insulin resistance and type 2 diabetes.

\section{How is central obesity linked to (hepatic) insulin resistance?}

As outlined above, there is a large body of clinical evidence suggesting a strong link between central (abdominal) fat accumulation and the development of insulin resistance and type 2 diabetes $(7-13,76)$. This relationship was found to be stronger than with measures of general 
obesity, such as BMI $(10,77)$. Moreover, lifestyle intervention-induced reduction in visceral fat mass was associated with improved insulin sensitivity suggesting that intra-abdominal fat accumulation may be causatively linked to insulin resistance (78). How does visceral fat accumulation impact on (hepatic) insulin sensitivity? It was suggested that increased release of lipids from omental and mesenteric adipose tissue in obesity results in increased portal FFA concentration (58), which in turn induce hepatic insulin resistance. Indeed, chronic exposure of the liver to elevated FFAs was previously found to inhibit the action of insulin and, consequently, to stimulate gluconeogenesis $(9,25,79-81)$. Accordingly, several gene transcripts involved in lipid turnover in omental fat and rate-limiting gluconeogenic enzymes in the liver were elevated in the fat-fed dog model (82). In addition, liver triglyceride content was increased and insulin receptor binding decreased. Moreover, infusion of FFAs induced peripheral and hepatic insulin resistance in humans $(83,84)$, whereas the lowering of FFA plasma levels enhanced insulininduced suppression of endogenous glucose production during hyperinsulinemic-euglycemic clamps in type 2 diabetic individuals (85). Thus, FFAs appear to be an important signal controlling endogenous glucose output $(86,87)$ and it is conceivable that in obesity increased flux of FFA from visceral fat depots to the liver will result in hepatic insulin resistance and hepatic steatosis (58). Consequently, the 'portal theory' has initially been explained by a relative high lipolysis rate specifically in visceral adipose tissue, which increases the portal concentration of FFAs in obesity leading to hepatic insulin resistance and metabolic abnormalities. However, we recently compared lipolysis rate in mesenteric adipocytes isolated from mice fed either a standard or fat-enriched diet and we unexpectedly found that basal lipolysis was not increased in mesenteric adipocytes isolated from high fat diet-fed mice (28). In accordance, FFA concentration in portal blood did not increase in high fat diet-fed animals even though they developed (hepatic) insulin resistance and steatosis. Similarly, Frayn et al. reported that the rates of FFA delivery were downregulated with maintained systemic plasma FFA concentrations in 
abdominally obese men, both in the fasted and postprandial state (88). Thus, the concept of obesity associated with elevated FFA levels may be questioned (89).

In the above mentioned study, we observed an increased release of pro-inflammatory cytokines such as IL-6 from mesenteric adipocytes of high-fat compared to standard diet fed mice (28). Accordingly, omental adipose tissue was previously reported to release two to three times more IL-6 than subcutaneous adipose tissue in obese subjects (90). Moreover, IL-6 levels were higher in portal vein compared to radial artery samples in obese individuals (91). In mice, IL-6 was previously shown to reduce insulin's ability to suppress basal endogenous glucose production during hyperinsulinemic-euglycemic clamps, indicating that IL-6 induced hepatic insulin resistance (92). Consistently, IL-6 concentration was elevated in various insulin-resistant mouse models (93) and treatment with IL-6 neutralizing antibody improved hepatic insulin sensitivity (94). Mechanistically, chronic IL-6 treatment suppresses insulin-dependent insulin receptor autophosphorylation and tyrosine phosphorylation of insulin receptor substrate 1 (IRS-1) in the liver of C57BL/6 mice (95), probably via stimulation of suppressor of cytokine signaling 3 (SOCS3). The latter suppresses insulin signaling via direct interaction with the insulin receptor $(96,97)$. In contrast, mice with a liver-specific deletion of the $I L-6$ receptor $\alpha$ gene exhibited reduced insulin sensitivity and glucose tolerance (98) suggesting that IL-6 at low concentration has permissive effects on insulin sensitivity and glucose metabolism, but at high concentration detrimental effects. Furthermore, muscle-derived IL-6 is now recognized as a major contributor to the mobilization of lipids during physical activity (99). Thus, the role of IL-6 in glucoregulatory processes may be neither exclusively beneficial nor harmful (100).

Besides IL-6 other pro-inflammatory cytokines such as IL-1 $\beta$ may be released in increasing amounts from visceral fat depots and contribute to hepatic insulin resistance. In obese individuals, elevated IL-1 $\beta$ expression and secretion was observed in visceral/omental compared to subcutaneous adipose tissue and to tissues from lean individuals (101-103). Consistently, IL$1 \beta$ release in human omental fat explants positively correlated with body mass index (104). In 
mice, IL-1 $\beta$ levels were significantly elevated in portal but not systemic blood after eight weeks of high fat diet when compared with regular chow diet (own observations and (104)). IL-1 $\beta$ treatment of hepatoma cell lines and primary rat hepatocytes induced insulin resistance in vitro. Moreover, conditioned medium from 3T3-L1 adipocytes pretreated with TNF $\alpha$ deteriorated insulin-signaling in Fao hepatoma cells IL-1 $\beta$-dependently suggesting a potential role of adipocyte-derived IL-1 $\beta$ as a mediator in the perturbed cross talk between adipocytes and liver cells in response to adipose tissue inflammation (104).

In summary, increased production and release of pro-inflammatory cytokines such as IL-6 and/or IL-1 $\beta$ from omental and mesenteric adipocytes into the portal vein may contribute to the development of hepatic insulin resistance. Thus, the 'portal theory' may be explained as an increased release of both FFAs and/or pro-inflammatory cytokines into the portal circulation (105). Presently, further studies are needed to confirm a significant contribution of proinflammatory cytokines to the 'portal theory'. Moreover, it is conceivable that obesity-associated changes in the composition of the gut microbiota and the resulting release of gut-derived proinflammatory and bacterial factors such as endotoxin may contribute to the 'portal theory' since large parts of the small bowel are also drained into the portal vein (106).

However, the hitherto presented data are mainly correlative and do not directly prove causality between central obesity (i.e. increased portally-drained visceral adipose tissue mass) and hepatic insulin resistance/deteriorated glucose metabolism. To directly test such causal link, both lipectomy and transplantation studies were performed. Results are controversial and not all of them support the 'portal theory' as outlined below.

\section{Direct evidence in support of the 'portal theory'}

In obese individuals, omentectomy performed together with gastric banding significantly improved glucose metabolism and insulin sensitivity (107). However, since individuals with both interventions lost on average an additional nine kilograms of body mass it remains unclear 
whether the observed metabolic improvement was due to the reduction in omental fat only or to the overall loss in fat mass $(107,108)$. In addition, two recent publications reported no additional benefit of omentectomy on insulin sensitivity in morbid obese people $(109,110)$. In rodents, several studies aimed to investigate the impact of lipectomy on glucose metabolism and, indeed, removal of epididymal and perirenal depots was reported to improve glucose metabolism (111, 112). However, since these depots are systemically drained, no conclusion regarding a potential detrimental effect of portally drained adipose tissue on (hepatic) insulin sensitivity can be drawn. Of interest, removal of small pieces of (portally drained) mesenteric adipose tissue improved glucose tolerance and hepatic triglyceride content in rats (113) supporting a potential role for the 'portal theory' in the pathogenesis of obesity-induced insulin resistance.

To directly test the hypothesis that portally drained visceral fat induces hepatic insulin resistance we performed fat transplantation experiments. To this end we transplanted epididymal fat depots from lean donor to healthy littermates (C57B16/J mice) either to systemically drained or to portally drained sites $(114,115)$. Only mice receiving portally drained fat transplants exhibited impaired glucose tolerance compared to sham-operated mice, whereas mice receiving systemically drained transplants revealed improved glucose tolerance. Moreover, hyperinsulinemic-euglycemic clamps revealed that insulin-induced suppression of endogenous glucose production was blunted in mice receiving portally drained fat transplants providing perhaps the most direct evidence yet supporting the 'portal theory'. In contrast to our study, two recent studies reported no changes or even improvement in glucose tolerance after epididymal or mesenteric fat transplantation into the abdominal cavity $(116,117)$. However, both studies provided no evidence for pure portal drainage of their fat transplants or as for the paper by Tran et al. it is assumed that fat pads were drained to both the caval as well as to the portal vein (117). Similarly, we found that mice receiving both a systemically as well as a portally drained fat transplant showed no net alteration in glucose tolerance (115). One potential explanation might be the fact that the beneficial metabolic effect of the systemically-drained fat transplant (114) was 
balanced by the detrimental effect of the portal-drained transplant. Intriguingly, expression of pro-inflammatory cytokines such as IL-6 was increased in transplanted fat pads and, consequently, concentration of IL-6 was increased in portal but not systemic circulation whereas FFA levels were not altered when compared to sham-operated mice. Moreover, mice receiving portally drained fat transplants from IL-6 deficient donors no longer developed hepatic insulin resistance. Such finding strongly argues for an important role for portally mediated proinflammatory cytokines in the development of hepatic insulin resistance and further supports a significant role for pro-inflammatory cytokines in the 'portal theory'.

\section{Evidence challenging the 'portal theory'}

Although numerous studies have shown evidence for a major role of (portally drained) visceral adipose tissue in the development of (hepatic) insulin resistance and metabolic diseases, its predominant contribution has been questioned $(22,108,118,119)$. The most common argument raised against the 'portal theory' states that insulin-mediated glucose disposal not only correlates inversely with visceral fat, but also with abdominal subcutaneous fat mass, indicating that the systemically drained subcutaneous adipose tissue may have detrimental effects on glucose homeostasis $(53,120-122)$. Although correlation studies highlight a potential association, they obviously do not prove causality. Moreover, abdominal subcutaneous fat mass itself strongly correlated with intraperitoneal fat mass in asymptomatic middle-aged men with a wide range of adiposity (53). Similarly, a strong correlation was reported for asymptomatic women $(118,123)$. Therefore, such studies do not necessarily argue against an important role of the 'portal theory' in the pathogenesis of obesity-associated insulin resistance.

Another argument often raised against the 'portal theory' is the finding that relative low amounts of FFAs originate from visceral adipose tissue. Since it is technically difficult to measure FFAs directly in the portal vein of humans, Jensen et al. developed an isotope dilution technique to measure systemic and regional FFA uptake and release indirectly (124). Using such 
attractive technique they were able to show that with increasing mass visceral fat depots released increasing amounts of FFAs into the portal vein, even though the relative contribution of any individual fat depot was quite variable (125). Most importantly, the relative amount of portal vein FFAs derived from visceral fat was suggested to be much less than the relative amount derived from lipolysis of subcutaneous fat. It was calculated that only approximately 5-30\% of portal vein FFAs originated from visceral fat in lean as well as in obese subjects. It was therefore concluded that visceral fat is not as important as subcutaneous fat in supplying FFAs to the liver both in lean and in obese individuals $(22,108,125)$. However, although the relative contribution of FFA from visceral fat to the systemic circulation is low, the direct exposure of the liver to FFAs derived from the portal vein may still have detrimental effects. In addition, the composition of FFA released from (visceral) adipose tissue may change in obesity. Furthermore, increased release of pro-inflammatory cytokines into portal circulation may play a more crucial role in the development of hepatic insulin resistance than increased FFA release as outlined above (105, $115)$.

\section{Conclusions and final remarks}

The 'portal theory' comprises the concept that direct exposure of the liver to increasing amounts of FFAs and/or pro-inflammatory factors released from visceral adipose tissue (and/or the gut) directly into the portal vein importantly contributes to the development of hepatic insulin resistance and hepatic steatosis (Fig. 2). Such notion is supported by the fact that omental and mesenteric adipose tissue have distinct functional properties compared to subcutaneous adipose tissue such as altered production and secretion pattern of adipocytokines in obesity. Moreover, ectopic storage of fat in tissues such as liver and skeletal muscle was proposed to play a crucial role in the development of insulin resistance and type 2 diabetes $(126,127)$ and, thus, in accordance with the 'portal theory' a decreased storage capacity especially of portally drained adipose tissue may oversupply the liver with lipids resulting in (ectopic) fat accumulation. We 
believe that we presented herein good clinical and experimental evidence in support of the "portal theory'. However, further studies are needed for a better and comprehensive understanding of the apparent causal link between visceral obesity and (hepatic) insulin resistance.

\section{Acknowledgments}

We would like to thank Prof. Assaf Rudich, Ben-Gurion University of the Negev, Israel, for helpful and highly appreciated discussion and Dr. Stephan Wueest for critical reading of the manuscript. We are grateful to Prof. Eugen Schoenle for continuous support. We would like to apologize to colleagues whose work has not been cited herein. DK is supported by grants from the Swiss National Science Foundation (310000-112275) and the European Foundation for the Study of Diabetes (EFSD-Lilly).

\section{References}

1. Ahima RS, Flier JS. Adipose tissue as an endocrine organ. Trends Endocrinol Metab 2000; 11: $327-332$.

2. Fruhbeck G, Gomez-Ambrosi J, Muruzabal FJ, Burrell MA. The adipocyte: a model for integration of endocrine and metabolic signaling in energy metabolism regulation. $\mathrm{Am} J$ Physiol Endocrinol Metab 2001; 280: E827-847.

3. Lazar MA. How obesity causes diabetes: not a tall tale. Science 2005; 307: 373-375.

4. Kloting N, Fasshauer M, Dietrich A, et al. Insulin-sensitive obesity. Am J Physiol Endocrinol Metab 2010; 299: E506-515.

5. Reitman ML, Arioglu E, Gavrilova O, Taylor SI. Lipoatrophy revisited. Trends Endocrinol Metab 2000; 11: 410-416.

6. Vague J. The degree of masculine differentiation of obesities: a factor determining predisposition to diabetes, atherosclerosis, gout, and uric calculous disease. Am J Clin Nutr 1956; 4: 20-34.

7. Bjorntorp P. Abdominal obesity and the development of noninsulin-dependent diabetes mellitus. Diabetes Metab Rev 1988; 4: 615-622.

8. Carey VJ, Walters EE, Colditz GA, et al. Body fat distribution and risk of non-insulindependent diabetes mellitus in women. The Nurses' Health Study. Am J Epidemiol 1997; 145: 614-619.

9. Kissebah AH, Krakower GR. Regional adiposity and morbidity. Physiol Rev 1994; 74: 761-811.

10. Ohlson LO, Larsson B, Svardsudd K, et al. The influence of body fat distribution on the incidence of diabetes mellitus. 13.5 years of follow-up of the participants in the study of men born in 1913. Diabetes 1985; 34: 1055-1058.

11. Pouliot MC, Despres JP, Nadeau A, et al. Visceral obesity in men. Associations with glucose tolerance, plasma insulin, and lipoprotein levels. Diabetes 1992; 41: 826-834. 
12. Wang Y, Rimm EB, Stampfer MJ, Willett WC, Hu FB. Comparison of abdominal adiposity and overall obesity in predicting risk of type 2 diabetes among men. Am J Clin Nutr 2005; 81: 555-563.

13. Zimmet P, Alberti KG, Shaw J. Global and societal implications of the diabetes epidemic. Nature 2001; 414: 782-787.

14. Misra A, Garg A, Abate N, Peshock RM, Stray-Gundersen J, Grundy SM. Relationship of anterior and posterior subcutaneous abdominal fat to insulin sensitivity in nondiabetic men. Obes Res 1997; 5: 93-99.

15. Snijder MB, Dekker JM, Visser M, et al. Associations of hip and thigh circumferences independent of waist circumference with the incidence of type 2 diabetes: the Hoorn Study. Am J Clin Nutr 2003; 77: 1192-1197.

16. Tanko LB, Bagger YZ, Alexandersen P, Larsen PJ, Christiansen C. Peripheral adiposity exhibits an independent dominant antiatherogenic effect in elderly women. Circulation 2003; 107: 1626-1631.

17. Porter SA, Massaro JM, Hoffmann U, Vasan RS, O'Donnel CJ, Fox CS. Abdominal subcutaneous adipose tissue: a protective fat depot? Diabetes Care 2009; 32: 1068-1075.

18. Snijder MB, Dekker JM, Visser M, et al. Larger thigh and hip circumferences are associated with better glucose tolerance: the Hoorn study. Obes Res 2003; 11: 104-111.

19. Bays HE, Fox KM, Grandy S. Anthropometric measurements and diabetes mellitus: clues to the "pathogenic" and "protective" potential of adipose tissue. Metab Syndr Relat Disord 2010; 8: 307-315.

20. Gallagher D, Kelley DE, Yim JE, et al. Adipose tissue distribution is different in type 2 diabetes. Am J Clin Nutr 2009; 89: 807-814.

21. Harris RB, Leibel RL. Location, location, location. Cell Metab 2008; 7: 359-361.

22. Miles JM, Jensen MD. Counterpoint: visceral adiposity is not causally related to insulin resistance. Diabetes Care 2005; 28: 2326-2328.

23. Yang X, Smith U. Adipose tissue distribution and risk of metabolic disease: does thiazolidinedione-induced adipose tissue redistribution provide a clue to the answer? Diabetologia 2007; 50: 1127-1139.

24. Arner P. Not all fat is alike. Lancet 1998; 351: 1301-1302.

25. Bjorntorp P. "Portal" adipose tissue as a generator of risk factors for cardiovascular disease and diabetes. Arteriosclerosis 1990; 10: 493-496.

26. Ostman J, Arner P, Engfeldt P, Kager L. Regional differences in the control of lipolysis in human adipose tissue. Metabolism 1979; 28: 1198-1205.

27. Bolinder J, Kager L, Ostman J, Arner P. Differences at the receptor and postreceptor levels between human omental and subcutaneous adipose tissue in the action of insulin on lipolysis. Diabetes 1983; 32: 117-123.

28. Wueest S, Yang X, Liu J, Schoenle EJ, Konrad D. Inverse regulation of basal lipolysis in perigonadal and mesenteric fat depots in mice. Am J Physiol Endocrinol Metab 2012; 302: E153-E160.

29. Caesar R, Manieri M, Kelder T, et al. A combined transcriptomics and lipidomics analysis of subcutaneous, epididymal and mesenteric adipose tissue reveals marked functional differences. PLoS One 2010; 5: e11525.

30. Edens NK, Fried SK, Kral JG, Hirsch J, Leibel RL. In vitro lipid synthesis in human adipose tissue from three abdominal sites. Am J Physiol 1993; 265: E374-379.

31. Koutsari C, Ali AH, Mundi MS, Jensen MD. Storage of circulating free fatty acid in adipose tissue of postabsorptive humans: quantitative measures and implications for body fat distribution. Diabetes 2011; 60: 2032-2040.

32. Montague CT, Prins JB, Sanders L, Digby JE, O'Rahilly S. Depot- and sex-specific differences in human leptin mRNA expression: implications for the control of regional fat distribution. Diabetes 1997; 46: 342-347. 
33. Van Harmelen V, Reynisdottir S, Eriksson P, Thorne A, Hoffstedt J, Lonnqvist F, et al. Leptin secretion from subcutaneous and visceral adipose tissue in women. Diabetes 1998; 47: 913-917.

34. Berg AH, Combs TP, Scherer PE. ACRP30/adiponectin: an adipokine regulating glucose and lipid metabolism. Trends Endocrinol Metab 2002; 13: 84-89.

35. Kim JY, van de Wall E, Laplante M, et al. Obesity-associated improvements in metabolic profile through expansion of adipose tissue. J Clin Invest 2007; 117: 2621-2637.

36. Yamauchi $\mathrm{T}$, Kamon J, Waki $\mathrm{H}$, et al. The fat-derived hormone adiponectin reverses insulin resistance associated with both lipoatrophy and obesity. Nat Med 2001; 7: 941-946.

37. Motoshima H, Wu X, Sinha MK, et al. Differential regulation of adiponectin secretion from cultured human omental and subcutaneous adipocytes: effects of insulin and rosiglitazone. J Clin Endocrinol Metab 2002; 87: 5662-5667.

38. Lafontan M, Berlan M. Do regional differences in adipocyte biology provide new pathophysiological insights? Trends Pharmacol Sci 2003; 24: 276-283.

39. Steppan CM, Lazar MA. Resistin and obesity-associated insulin resistance. Trends Endocrinol Metab 2002; 13: 18-23.

40. Yang Q, Graham TE, Mody N, et al. Serum retinol binding protein 4 contributes to insulin resistance in obesity and type 2 diabetes. Nature 2005; 436: 356-362.

41. Rajala MW, Obici S, Scherer PE, Rossetti L. Adipose-derived resistin and gut-derived resistin-like molecule-beta selectively impair insulin action on glucose production. $J$ Clin Invest 2003; 111: 225-230.

42. McTernan CL, McTernan PG, Harte AL, Levick PL, Barnett AH, Kumar S. Resistin, central obesity, and type 2 diabetes. Lancet 2002; 359: 46-47.

43. Kloting N, Graham TE, Berndt J, et al. Serum retinol-binding protein is more highly expressed in visceral than in subcutaneous adipose tissue and is a marker of intraabdominal fat mass. Cell Metab 2007; 6: 79-87.

44. Ouchi N, Parker JL, Lugus JJ, Walsh K. Adipokines in inflammation and metabolic disease. Nature reviews. Immunology 2011; 11: 85-97.

45. Vohl MC, Sladek R, Robitaille J, et al. A survey of genes differentially expressed in subcutaneous and visceral adipose tissue in men. Obes Res 2004; 12: 1217-1222.

46. Yamamoto Y, Gesta S, Lee KY, Tran TT, Saadatirad P, Kahn CR. Adipose depots possess unique developmental gene signatures. Obesity 2010; 18: 872-878.

47. Tchkonia T, Giorgadze N, Pirtskhalava T, et al. Fat depot-specific characteristics are retained in strains derived from single human preadipocytes. Diabetes 2006; 55: 25712578.

48. Tchkonia $\mathrm{T}$, Lenburg M, Thomou $\mathrm{T}$, et al. Identification of depot-specific human fat cell progenitors through distinct expression profiles and developmental gene patterns. $A m J$ Physiol Endocrinol Metab 2007; 292: E298-E307.

49. Gesta S, Tseng YH, Kahn CR. Developmental origin of fat: tracking obesity to its source. Cell 2007; 131: 242-256.

50. Petrovic N, Walden TB, Shabalina IG, Timmons JA, Cannon B, Nedergaard J. Chronic peroxisome proliferator-activated receptor gamma (PPARgamma) activation of epididymally derived white adipocyte cultures reveals a population of thermogenically competent, UCP1-containing adipocytes molecularly distinct from classic brown adipocytes. J Biol Chem 2010; 285: 7153-7164.

51. Walden TB, Hansen IR, Timmons JA, Cannon B, Nedergaard J. Recruited versus nonrecruited molecular signatures of brown, "brite" and white adipose tissues. Am J Physiol Endocrinol Metab 2012; 302: E19-E31.

52. Virtanen KA, Nuutila P. Brown adipose tissue in humans. Curr Opin Lipidol 2011; 22: 4954. 
53. Abate N, Garg A, Peshock RM, Stray-Gundersen J, Grundy SM. Relationships of generalized and regional adiposity to insulin sensitivity in men. $J$ Clin Invest 1995; 96: 8898.

54. Gaidhu MP, Anthony NM, Patel P, Hawke TJ, Ceddia RB. Dysregulation of lipolysis and lipid metabolism in visceral and subcutaneous adipocytes by high-fat diet: role of ATGL, HSL, and AMPK. Am J Physiol Cell Physiol 2010; 298: C961-C971.

55. Joe AW, Yi L, Even Y, Vogl AW, Rossi FM. Depot-specific differences in adipogenic progenitor abundance and proliferative response to high-fat diet. Stem Cells 2009; 27: 2563-2570.

56. Macotela Y, Boucher J, Tran TT, Kahn CR. Sex and depot differences in adipocyte insulin sensitivity and glucose metabolism. Diabetes 2009; 58: 803-812.

57. Okamoto Y, Higashiyama H, Rong JX, et al. Comparison of mitochondrial and macrophage content between subcutaneous and visceral fat in $\mathrm{db} / \mathrm{db}$ mice. Exp Mol Pathol 2007; 83: 73-83.

58. Bergman RN, Ader M. Free fatty acids and pathogenesis of type 2 diabetes mellitus. Trends Endocrinol Metab 2000; 11: 351-356.

59. Boden G. Role of fatty acids in the pathogenesis of insulin resistance and NIDDM. Diabetes 1997; 46: 3-10.

60. Weisberg SP, McCann D, Desai M, Rosenbaum M, Leibel RL, Ferrante AW, Jr. Obesity is associated with macrophage accumulation in adipose tissue. J Clin Invest 2003; 112: 17961808.

61. Xu H, Barnes GT, Yang Q, et al. Chronic inflammation in fat plays a crucial role in the development of obesity-related insulin resistance. J Clin Invest 2003; 112: 1821-1830.

62. Feuerer M, Herrero L, Cipolletta D, et al. Lean, but not obese, fat is enriched for a unique population of regulatory T cells that affect metabolic parameters. Nat Med 2009; 15: 930939.

63. Nishimura S, Manabe I, Nagasaki M, et al. CD8+ effector T cells contribute to macrophage recruitment and adipose tissue inflammation in obesity. Nat Med 2009; 15:914-920.

64. Schymeinsky J, Mocsai A, Walzog B. Neutrophil activation via beta2 integrins (CD11/CD18): molecular mechanisms and clinical implications. Thromb Haemost 2007; 98: $262-273$.

65. Elgazar-Carmon V, Rudich A, Hadad N, Levy R. Neutrophils transiently infiltrate intraabdominal fat early in the course of high-fat feeding. J Lipid Res 2008; 49: 1894-1903.

66. Liu J, Divoux A, Sun J, et al. Genetic deficiency and pharmacological stabilization of mast cells reduce diet-induced obesity and diabetes in mice. Nat Med 2009; 15: 940-945.

67. Winer DA, Winer S, Shen L, et al. B cells promote insulin resistance through modulation of T cells and production of pathogenic IgG antibodies. Nat Med 2011; 17: 610-617.

68. Winer S, Chan Y, Paltser G, Truong D, Tsui H, Bahrami J, et al. Normalization of obesityassociated insulin resistance through immunotherapy. Nat Med 2009; 15: 921-929.

69. Park SY, Cho YR, Kim HJ, et al. Unraveling the temporal pattern of diet-induced insulin resistance in individual organs and cardiac dysfunction in C57BL/6 mice. Diabetes 2005; 54: 3530-3540.

70. Poirier H, Shapiro JS, Kim RJ, Lazar MA. Nutritional supplementation with trans-10, cis12-conjugated linoleic acid induces inflammation of white adipose tissue. Diabetes 2006; 55: 1634-1641.

71. Ehses JA, Meier DT, Wueest S, et al. Toll-like receptor 2-deficient mice are protected from insulin resistance and beta cell dysfunction induced by a high-fat diet. Diabetologia 2010; 53: $1795-1806$.

72. Nguyen MT, Favelyukis S, Nguyen AK, et al. A subpopulation of macrophages infiltrates hypertrophic adipose tissue and is activated by free fatty acids via Toll-like receptors 2 and 4 and JNK-dependent pathways. J Biol Chem 2007; 282: 35279-35292. 
73. Shi H, Kokoeva MV, Inouye K, Tzameli I, Yin H, Flier JS. TLR4 links innate immunity and fatty acid-induced insulin resistance. J Clin Invest 2006; 116: 3015-3025.

74. Holzer RG, Park EJ, Li N, et al. Saturated fatty acids induce c-Src clustering within membrane subdomains, leading to JNK activation. Cell 2011; 147: 173-184.

75. Nakamura T, Furuhashi M, Li P, et al. Double-stranded RNA-dependent protein kinase links pathogen sensing with stress and metabolic homeostasis. Cell 2010; 140: 338-348.

76. Alberti KG, Zimmet P, Shaw J. The metabolic syndrome--a new worldwide definition. Lancet 2005; 366: 1059-1062.

77. Lapidus L, Bengtsson C, Larsson B, Pennert K, Rybo E, Sjostrom L. Distribution of adipose tissue and risk of cardiovascular disease and death: a 12 year follow up of participants in the population study of women in Gothenburg, Sweden. Br Med J 1984; 289: $1257-1261$.

78. Kantartzis K, Machann J, Schick F, et al. Effects of a lifestyle intervention in metabolically benign and malign obesity. Diabetologia 2011; 54: 864-868.

79. Exton JH, Corbin JG, Park CR. Control of gluconeogenesis in liver. IV. Differential effects of fatty acids and glucagon on ketogenesis and gluconeogenesis in the perfused rat liver. $J$ Biol Chem 1969; 244: 4095-4102.

80. Svedberg J, Bjorntorp P, Smith U, Lonnroth P. Free-fatty acid inhibition of insulin binding, degradation, and action in isolated rat hepatocytes. Diabetes 1990; 39: 570-574.

81. Williamson JR, Kreisberg RA, Felts PW. Mechanism for the stimulation of gluconeogenesis by fatty acids in perfused rat liver. Proc Natl Acad Sci USA 1966; 56: 247-254.

82. Kabir M, Catalano KJ, Ananthnarayan S, et al. Molecular evidence supporting the portal theory: a causative link between visceral adiposity and hepatic insulin resistance. $A m J$ Physiol Endocrinol Metab 2005; 288: E454-E461.

83. Ferrannini E, Barrett EJ, Bevilacqua S, DeFronzo RA. Effect of fatty acids on glucose production and utilization in man. J Clin Invest 1983; 72: 1737-1747.

84. Kelley DE, Mokan M, Simoneau JA, Mandarino LJ. Interaction between glucose and free fatty acid metabolism in human skeletal muscle. J Clin Invest 1993; 92: 91-98.

85. Saloranta C, Franssila-Kallunki A, Ekstrand A, Taskinen MR, Groop L. Modulation of hepatic glucose production by non-esterified fatty acids in type 2 (non-insulin-dependent) diabetes mellitus. Diabetologia 1991; 34: 409-415.

86. Bergman RN, Mittelman SD. Central role of the adipocyte in insulin resistance. $J$ Basic Clin Physiol Pharmacol 1998; 9: 205-221.

87. Rebrin K, Steil GM, Mittelman SD, Bergman RN. Causal linkage between insulin suppression of lipolysis and suppression of liver glucose output in dogs. J Clin Invest 1996; 98: 741-749.

88. McQuaid SE, Hodson L, Neville MJ, et al. Downregulation of adipose tissue fatty acid trafficking in obesity: a driver for ectopic fat deposition? Diabetes 2011; 60: 47-55.

89. Karpe F, Dickmann JR, Frayn KN. Fatty acids, obesity, and insulin resistance: time for a reevaluation. Diabetes 2011; 60: 2441-2449.

90. Fried SK, Bunkin DA, Greenberg AS. Omental and subcutaneous adipose tissues of obese subjects release interleukin-6: depot difference and regulation by glucocorticoid. $J$ Clin Endocrinol Metab 1998; 83: 847-850.

91. Fontana L, Eagon JC, Trujillo ME, Scherer PE, Klein S. Visceral fat adipokine secretion is associated with systemic inflammation in obese humans. Diabetes 2007; 56: 1010-1013.

92. Kim HJ, Higashimori T, Park SY, et al. Differential effects of interleukin-6 and -10 on skeletal muscle and liver insulin action in vivo. Diabetes 2004; 53: 1060-1067.

93. Wueest S, Rapold RA, Schumann DM, et al. Deletion of Fas in adipocytes relieves adipose tissue inflammation and hepatic manifestations of obesity in mice. J Clin Invest 2010; 120: 191-202. 
94. Sabio G, Das M, Mora A, et al. A stress signaling pathway in adipose tissue regulates hepatic insulin resistance. Science 2008; 322: 1539-1543.

95. Klover PJ, Zimmers TA, Koniaris LG, Mooney RA. Chronic exposure to interleukin-6 causes hepatic insulin resistance in mice. Diabetes 2003; 52: 2784-2789.

96. Senn JJ, Klover PJ, Nowak IA, Mooney RA. Interleukin-6 induces cellular insulin resistance in hepatocytes. Diabetes 2002; 51: 3391-3399.

97. Senn JJ, Klover PJ, Nowak IA, et al. Suppressor of cytokine signaling-3 (SOCS-3), a potential mediator of interleukin-6-dependent insulin resistance in hepatocytes. $J$ Biol Chem 2003; 278: 13740-13746.

98. Wunderlich FT, Strohle P, Konner AC, et al. Interleukin-6 signaling in liver-parenchymal cells suppresses hepatic inflammation and improves systemic insulin action. Cell Metab 2010; 12: 237-249.

99. Pedersen BK, Steensberg A, Keller P, et al. Muscle-derived interleukin-6: lipolytic, antiinflammatory and immune regulatory effects. Pflugers Arch 2003; 446: 9-16.

100. Carey AL, Febbraio MA. Interleukin-6 and insulin sensitivity: friend or foe? Diabetologia 2004; 47: 1135-1142.

101. Juge-Aubry CE, Somm E, Chicheportiche R, et al. Regulatory effects of interleukin (IL)-1, interferon-beta, and IL-4 on the production of IL-1 receptor antagonist by human adipose tissue. J Clin Endocrinol Metab 2004; 89: 2652-2658.

102. Maury E, Ehala-Aleksejev K, Guiot Y, Detry R, Vandenhooft A, Brichard SM. Adipokines oversecreted by omental adipose tissue in human obesity. Am J Physiol Endocrinol Metab 2007; 293: E656-665.

103. Moschen AR, Molnar C, Enrich B, Geiger S, Ebenbichler CF, Tilg H. Adipose and liver expression of interleukin (IL)-1 family members in morbid obesity and effects of weight loss. Mol Med 2011; 17: 840-845.

104. Nov O, Kohl A, Lewis EC, et al. Interleukin-1beta may mediate insulin resistance in liverderived cells in response to adipocyte inflammation. Endocrinology 2010; 151: 4247-456.

105. Catalano KJ, Stefanovski D, Bergman RN. Critical role of the mesenteric depot versus other intra-abdominal adipose depots in the development of insulin resistance in young rats. Diabetes 2010: 59: 1416-1423.

106. Cani PD, Bibiloni $\mathrm{R}$, Knauf $\mathrm{C}$, et al. Changes in gut microbiota control metabolic endotoxemia-induced inflammation in high-fat diet-induced obesity and diabetes in mice. Diabetes 2008; 57: 1470-1481.

107. Thorne A, Lonnqvist F, Apelman J, Hellers G, Arner P. A pilot study of long-term effects of a novel obesity treatment: omentectomy in connection with adjustable gastric banding. Int J Obes Relat Metab Disord 2002; 26: 193-199.

108. Jensen MD. Is visceral fat involved in the pathogenesis of the metabolic syndrome? Human model. Obesity Suppl 2006; 14/1: 20S-24S.

109. Csendes A, Maluenda F, Burgos AM. A prospective randomized study comparing patients with morbid obesity submitted to laparotomic gastric bypass with or without omentectomy. Obes Surg 2009; 19: 490-494.

110. Fabbrini E, Tamboli RA, Magkos F, et al. Surgical removal of omental fat does not improve insulin sensitivity and cardiovascular risk factors in obese adults. Gastroenterology 2010; 139: 448-455.

111. Barzilai N, She L, Liu BQ, et al. Surgical removal of visceral fat reverses hepatic insulin resistance. Diabetes 1999; 48: 94-98.

112. Gabriely I, Ma XH, Yang XM, et al. Removal of visceral fat prevents insulin resistance and glucose intolerance of aging: an adipokine-mediated process? Diabetes 2002; 51:29512958. 
113. Foster MT, Shi H, Seeley RJ, Woods SC. Removal of intra-abdominal visceral adipose tissue improves glucose tolerance in rats: role of hepatic triglyceride storage. Physiol Behav 2011; 104: 845-854.

114. Konrad D, Rudich A, Schoenle EJ. Improved glucose tolerance in mice receiving intraperitoneal transplantation of normal fat tissue. Diabetologia 2007; 50: 833-839.

115. Rytka JM, Wueest S, Schoenle EJ, Konrad D. The portal theory supported by venous drainage-selective fat transplantation. Diabetes 2011; 60: 56-63.

116. Foster MT, Shi H, Softic S, Kohli R, Seeley RJ, Woods SC. Transplantation of nonvisceral fat to the visceral cavity improves glucose tolerance in mice: investigation of hepatic lipids and insulin sensitivity. Diabetologia 2011; 54: 2890-2899.

117. Tran TT, Yamamoto Y, Gesta S, Kahn CR. Beneficial effects of subcutaneous fat transplantation on metabolism. Cell Metab 2008; 7: 410-420.

118. Frayn KN. Visceral fat and insulin resistance--causative or correlative? Br J Nutr Suppl 2000; 83/1: S71-S77.

119. Ravussin E, Smith SR. Increased fat intake, impaired fat oxidation, and failure of fat cell proliferation result in ectopic fat storage, insulin resistance, and type 2 diabetes mellitus. Ann N Y Acad Sci 2002; 967: 363-378.

120. Abate N, Garg A, Peshock RM, Stray-Gundersen J, Adams-Huet B, Grundy SM. Relationship of generalized and regional adiposity to insulin sensitivity in men with NIDDM. Diabetes 1996; 45: 1684-1693.

121. Banerji MA, Chaiken RL, Gordon D, Kral JG, Lebovitz HE. Does intra-abdominal adipose tissue in black men determine whether NIDDM is insulin-resistant or insulin-sensitive? Diabetes 1995; 44: 141-146.

122. Goodpaster BH, Thaete FL, Simoneau JA, Kelley DE. Subcutaneous abdominal fat and thigh muscle composition predict insulin sensitivity independently of visceral fat. Diabetes 1997; 46: 1579-1585.

123. Thomas EL, Saeed N, Hajnal JV, et al. Magnetic resonance imaging of total body fat. $J$ Appl Physiol 1998; 85:1778-1785.

124. Jensen MD, Cardin S, Edgerton D, Cherrington A. Splanchnic free fatty acid kinetics. Am J Physiol Endocrinol Metab 2003; 284: E1140-E1148.

125. Nielsen S, Guo Z, Johnson CM, Hensrud DD, Jensen MD. Splanchnic lipolysis in human obesity. J Clin Invest 2004; 113: 1582-1588.

126. Heilbronn L, Smith SR, Ravussin E. Failure of fat cell proliferation, mitochondrial function and fat oxidation results in ectopic fat storage, insulin resistance and type II diabetes mellitus. Int J Obes Relat Metab Disord Suppl 2004; 28/4: S12-S21.

127. Rasouli N, Molavi B, Elbein SC, Kern PA. Ectopic fat accumulation and metabolic syndrome. Diabetes Obes Metab 2007; 9: 1-10. 


\section{Fig. 1 Intra-abdominal adipose tissue compromises different fat depots}

Venous drainage differs between intra-abdominal fat depots both in mice and humans: Omental fat, which is insignificant in rodents, is drained by the portal vein (yellow). Mesenteric adipose tissue compromises fat depots surrounding the small bowel (light green) and the colon (dark green). These fat depots are drain to the portal vein (yellow) except for the fat tissue surrounding the lowest part of the colon (rectum), which is drained to the vena cava inferior, i.e. systemically (grey). All other intra-abdominal fat depots such as the perirenal, the retroperitoneal and the perigonadal adipose tissue are drained by the inferior caval vein (systemically). Yellow stained fat depots: drained to the portal vein; grey stained fat depots: drained to the vena cava inferior.

\section{Fig. 2 Proposed mechanisms for visceral obesity-induced insulin resistance ('portal theory')}

Individuals with central obesity accumulate fat mainly in intra-abdominal deposits, i.e. in mesenteric and/or omental adipose tissue. The concomitant increased release of free fatty acids and/or pro-inflammatory factors from these depots are drained via the portal vein directly to the liver. Additionally, increased release of gut-derived pro-inflammatory and bacterial factors such as endotoxin might contribute to the 'portal theory' since large parts of the small bowel are also drained into the portal vein. Hepatic exposure to these factors will result in the development of hepatic insulin resistance, steatosis and inflammation. 


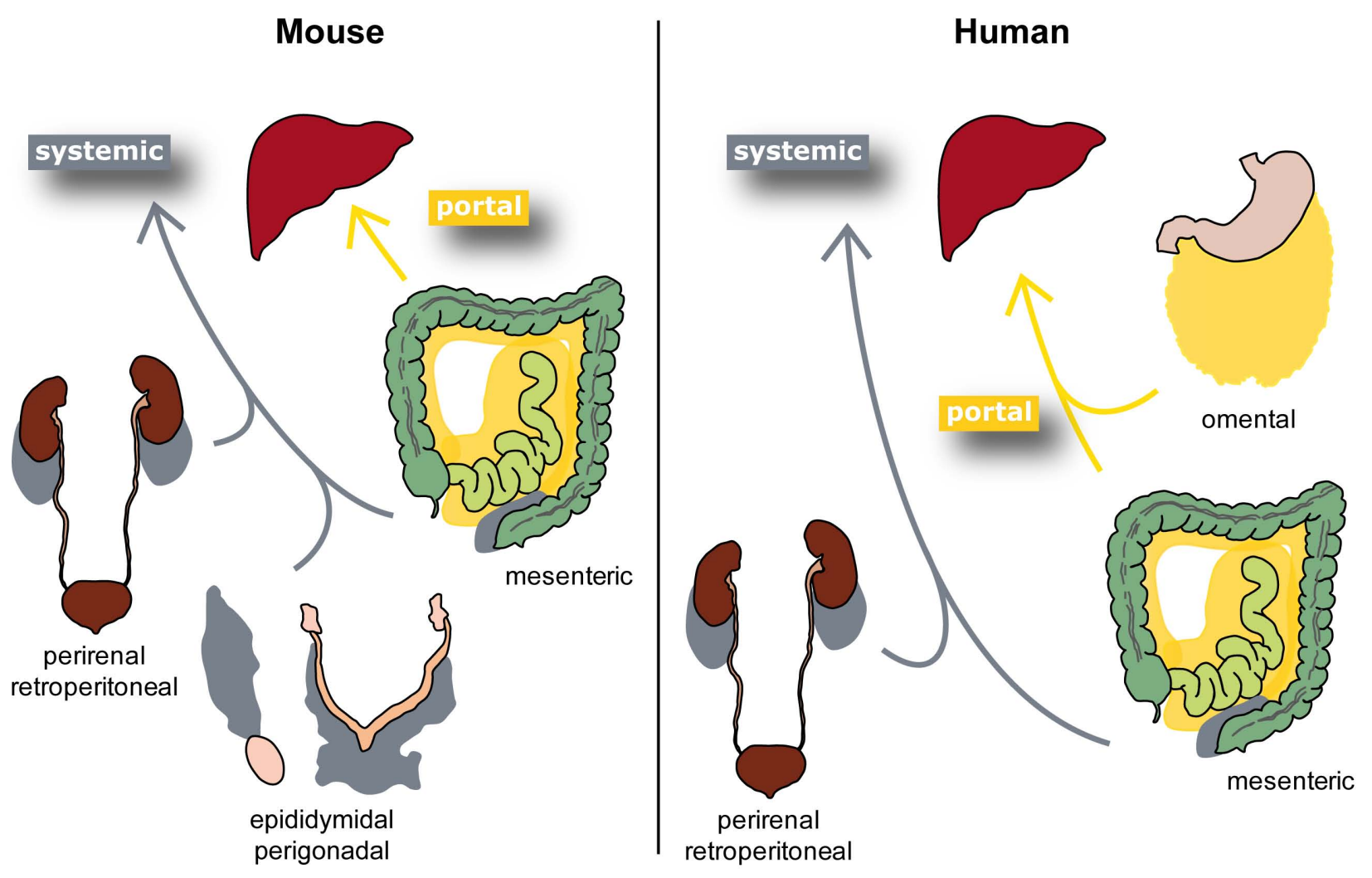




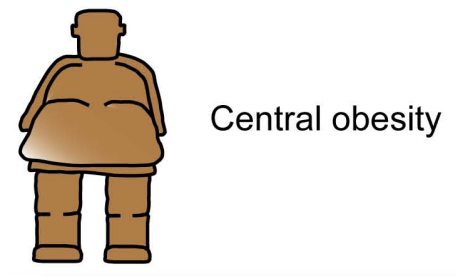

\section{Mesenteric / omental adipose tissue}

Adiponectin $\downarrow$

Free fatty $\uparrow$ ?

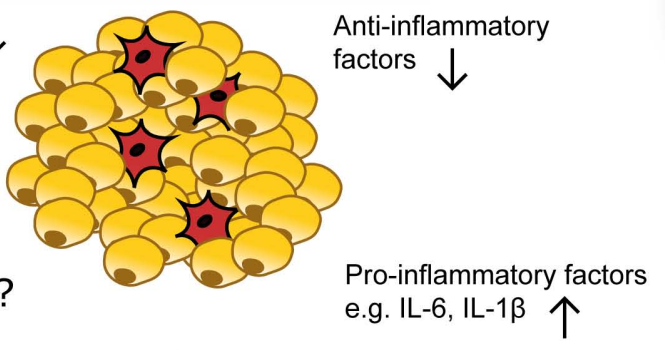

nower

个ene transcripts involved in lipid turnover and gluconeogenesis

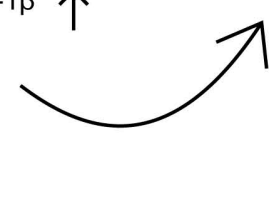

Insulin resistance

Steatosis

Inflammation

\section{Liver}

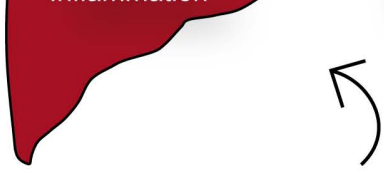

5

\section{Portal vein}

Intestine

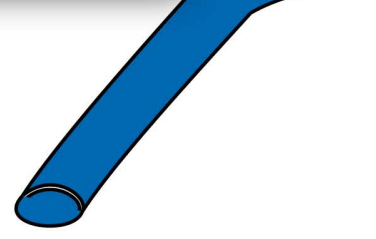

Bacterial factors e.g. endotoxins

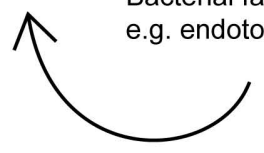

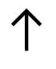



Pro-inflammatory factors 